\title{
ABSORPTION OF THE PESTICIDE PROPANIL ON AGRICULTURAL WASTE PRODUCTS
}

\author{
W:U.P. DE. ZOYSA and A.S. AMARASEKARA* \\ Department of Chemistry, University of Colombo, P.O. Box 1490, Colombo 3.
}

(Received: 27 July 1994 ; accepted: 07 December 1994)

\begin{abstract}
Propanil is one of the major pesticides used in Sri Lankan rice cultivation. This agrochemical can cause serious environmental pollution on leaching into the ground water system. The absorption of propanil by paddy hull, paddy hull ash, coir dust and saw dust were studied under laboratory conditions. The absorption of the active ingredient of propanil, 3,4-dichloropropionanilide $(3,4 \mathrm{DPA})$ from water solutions was studied by leaving the suspension for $48 \mathrm{~h}$ at room temperature. The amount of 3,4 DPA left after this period was estimated by HPLC. Absorption rates of 3,4 DPA on different absorbents were studied by analysing the solutions at different time intervals. According to the results obtained paddy hull has the highest absorption capacity and paddy hull ash has the lowest absorption capacity.
\end{abstract}

Key words: Agricultural waste, paddy hull, pesticides, propanil.

\section{INTRODUCTION}

Environmental pollution due to pesticides has increased dramatically in recent times in the country. Pesticides used in agriculture are subjected to a number of processes such as surface run off, absorption by the soil, leaching into the ground water, metabolism by soil micro organisms, volatilization and photodecomposition. Pollution of the water system has a particularly pronounced effect on the rural population of Sri Lanka who depend on ground water and naturally occurring water bodies and rivers for their water supply. Biological control of pests and the use of biodegradable pesticides minimize the pollution, however where the existing non-biodegradable pesticides have to be used, absorbents may be used to reduce the pesticide concentrations in polluted waters. ${ }^{1,2}$ The use of agricultural waste products as absorption materials is an attractive proposition. ${ }^{3}$ Propanil is a commonly used pesticide in Sri Lanka. In this study the absorption of the active ingredient of propanil, 3,4-dichloropropionanilide (3,4 DPA) by four common agricultural wastes, paddy hull, paddy hull ash, coir dust and saw dust was investigated.

\section{METHODS AND MATERIALS}

The formulated product propanil with $36 \%$ of the active ingredịent 3,4 DPA from Ceylon Petroleum Corporation was used. An authentic sample of 3,4 DPA in acetone $(3.63 \mathrm{mg} / \mathrm{ml})$ was employed for calibration. Double distilled water was used in the preparation of the solutions. Paddy hull (PH), paddy hull ash (PHA), coir dust (CD) and saw dust (SD) collected from Gampaha district were used as absorbents. JASCO HPLC (PU 980) with a reverse phase column ( Finepak SIL C-18-5) and a uv/visible detector coupled to an integrator were used for the analysis.

* Corresponding author. 
After several trials the following set of conditions were set up for the optimization of sensitivity of the final analysis. Solvent system : $65 \%$ methanol - $35 \%$ water, Flow rate : $1.5 \mathrm{ml} / \mathrm{min}$, Detection wavelength : $240 \mathrm{~nm}$. A series of 1, 2, 5, 10 and 15 ppm 3,4 DPA in water solution were prepared as standards and $25 \mu l$ aliquots were injected for analysis.

Preparation of test samples and control samples : $25 \mathrm{ml}$ of $20 \mathrm{ppm}$ formulated product in water was employed as the control sample. Three separate samples were prepared for each test material. In each case $1 \mathrm{~g}$ of the absorbent was suspended in $25 \mathrm{ml}$ of $20 \mathrm{ppm}$ formulated product in water solution.

Analysis procedure - HPLC quantification : All test samples were allowed to stand at room temperature $\left(29 \pm 1^{\circ} \mathrm{C}\right)$ for $48 \mathrm{~h}$ before the HPLC analysis. In all cases peak area, peak height and the retention time of the quantifying peak were measured and the concentrations were calculated on the basis of peak area values.

Rate of absorption of pesticide by test material : $1 \mathrm{~g}$ of each test material was suspended in $25 \mathrm{ml}$ of $20 \mathrm{ppm}$ formulated product in water solution and from each test material two samples were prepared. Then $20 \mu \mathrm{l}$ samples were taken from each test sample after $0.5,1.5,4.0$ and $7.0 \mathrm{~h}$ and subjected to HPLC analysis. Peak areas of the quantifying peak were measured and these values were then converted to concentrations using the standard curve. $25 \mathrm{ml}$ of $20 \mathrm{ppm}$ formulated product in water solution was employed as a control.

\section{RESULTS}

The concentration of $3,4 \mathrm{DPA}$ in $20 \mathrm{ppm}$ formulated product solution was found to be $5.433 \pm 0.032 \mathrm{ppm}$.

Table 1 shows the results of the absorption study after $48 \mathrm{~h}$, showing the remaining concentration of the $3,4 \mathrm{DPA}$ of $20 \mathrm{ppm}$ formulated product solution after absorption of the pesticide by each test material. The results of the rate of absorption study are shown in table 2 .

Table 1: Absorption of 3,4 DPA by agricultural wastes after a $48 \mathrm{~h}$ period.

\begin{tabular}{lccc}
\hline \multicolumn{2}{c}{$\begin{array}{c}\text { Remaining conc. of } \\
3,4 \text { DPA }(\mathrm{ppm})\end{array}$} & $\begin{array}{c}\text { Amount absorbed } \\
(\mathrm{ppm})\end{array}$ & \% Absorption \\
\hline PHA & $3.563 \pm 0.030$ & $1.907 \pm 0.044$ & $35 \pm 1$ \\
PH & $0.431 \pm 0.055$ & $5.012 \pm 0.064$ & $92 \pm 1$ \\
SD & $0.612 \pm 0.054$ & $4.831 \pm 0.063$ & $89 \pm 1$ \\
CD & $1.046 \pm 0.052$ & $4.397 \pm 0.061$ & $88 \pm 1$ \\
\hline
\end{tabular}


Table 2: Rate of absorption of 3,4 DPA by agricultural waster.

\begin{tabular}{lcccc}
\hline & \multicolumn{4}{c}{ \% absorption } \\
Time (h) & $0.5 \mathrm{~h}$ & $1.5 \mathrm{~h}$ & $4.0 \mathrm{~h}$ & $7.0 \mathrm{~h}$ \\
\hline PHA & 15 & 21 & 21 & 27 \\
PH & 46 & 67 & 81 & 86 \\
SD & 58 & 75 & 82 & 85 \\
CD & 33 & 58 & 67 & 70 \\
\hline
\end{tabular}

* Percentage absorption is the mean of duplicate experiments.

\section{DISCUSSION}

Paddy hull samples show the highest (92\%) and paddy hull ash the lowest (35\%) absorption of the pesticide after a $48 \mathrm{~h}$ period. Of the four samples tested, three (paddy hull, coir dust and saw dust) show more than $85 \%$ absorption of 3,4 DPA. The results of rates of absorption study suggest that saw dust has the highest initial rate of absorption of 3,4 DPA, but after $7 \mathrm{~h}$ the amounts of 3,4 DPA absorbed by saw dust, paddy hull and coir dust are about the same. The results indicate that paddy hull, saw dust and coir dust could be easily employed as absorbents for propanil pesticide. However their utilization under field conditions remains to be established.

\section{References}

1. Diamdopoulos E., Samaras P. \& Sakellaropoulos G.P. (1992). The effect of activated carbon properties on the absorption of toxic substances. Water Science Technology 25(1): 153-160.

2. Pribazari M., Daniel H., Badriyha B. \& Miltner R.J.(1991). Granular activated carbon for removal of chlorinated pesticides. Journal of Environmental Engineering (New York) 117(1): 80-100.

3. Masakio U., Yoshiki O., Hiroshi N., Kitamura E. \& Machico S. (1991). Basic study on removal of pesticides in drain water of golf links. Nara Ken Eisei Kenkyusho Nembo. (26): 112-115. (Abstract in English : Chemical Abstracts, (1991) 118, 197713-u). 